\title{
Study About the Design and Experiments of the Vibrating Resistance Reduction Force Measuring Device
}

\author{
Lili Xin ${ }^{*}$, , Chuanqi $\mathrm{Li}^{1}$ and Jihui Liang ${ }^{2}$ \\ ${ }^{1}$ College of Engineering, Shenyang Agricultural University, Shenyang, China \\ ${ }^{2}$ School of Automobile and Trafic, Shenyang Ligong University, Shenyang, China
}

\begin{abstract}
The force measuring device is designed to the study of the relationship between vibration amplitude, frequency, speed and traction resistance of the tractor If the design of the force measuring device which consists of a force measuring frame and three octagonal ring transducers is successful, the goal of real-time monitoring of the traction resistance in the process of vibrating sub soil may be reached. Also, the up, down, left and right margin of frame is designed to be adjustable, so that different kinds of tractor could link up with the force measuring device. With the vibrating sub-soiler machine, the vibrating resistance reduction experiments, which are mainly based on the change of the vibration amplitude, frequency and the speed of the tractor, may be done. The three levels of the vibration amplitude, frequency, and speed are as follows: vibration amplitude: $0.001 \mathrm{~m}, 0.002 \mathrm{~m}$, and $0.003 \mathrm{~m}$; frequency: $9 \mathrm{~Hz}, 10 \mathrm{~Hz}$, and $12 \mathrm{~Hz}$; speed: $0.1 \mathrm{~m} / \mathrm{s}, 0.2$ $\mathrm{m} / \mathrm{s}$, and $0.3 \mathrm{~m} / \mathrm{s}$. The experiment results showed that with the same speed and bigger vibration frequency, the tractor traction resistance is small and when the amplitude is $0.001 \mathrm{~m}$, the vibration frequency is $10 \mathrm{~Hz}$, and forward speed is 0.2 $\mathrm{m} / \mathrm{s}$, and the tractor traction resistance is the minimum.
\end{abstract}

Keywords: Design, experiment, force measuring frame, resistance reduction, vibration.

\section{INTRODUCTION}

Scholars and researchers have done extensive research about the study of the relationship between vibration parameters and drawing resistance and great achievements have been achieved in the field [1-7].

Li Xia et al. installed the drawing force transducer between a drawing tractor and a hanging tractor passively drawn behind. Measured the traction resistance of the entire unit and then measured the traction resistance of the trailing tractor. The subtraction of both is the traction. Besides, the octagonal ring transducer which is linked to the test knife through the rod on the one side and linked to the frame on the other side is used by Zhao Xin et al. in the test of soil reaction. Chen. $\mathrm{Y}$ et al. designed the double extended octagonal ring transducer force measuring device which shows the traction resistance in its horizontal data [8-23].

The force measuring device is studied and designed in the paper for the real-time monitoring of the traction resistance. With the vibratory subsoiler, the experiments of vibratory resistance reduction and the study of the relationship between vibration amplitude, frequency, forward speed and tractor's traction resistance are done. As a result, the optimal mode of vibratory tillage machine which has good sub soiling effect and small energy is obtained.

\section{DESIGN OF THE FORCE MEASURING DEVICE}

\subsection{Design of the Octagonal Ring Transducer}

The force measuring device consists of a force measuring frame and three octagonal ring transducers. Also, the up, down, left and right margin of frame is designed to be adjustable, so that different kinds of tractors could link up with the force measuring device. The vertical force, horizontal force and moment could be measured by the octagonal ring transducers.

The measuring range of the octagonal ring transducer designed is $0-10 \mathrm{kN}$. Diagram of the octagonal ring transducer is shown in Fig. (1). Material of the transducer is $40 \mathrm{Cr}$; yield limit is $\sigma_{s}=785 \mathrm{MPa}$; modulus of elasticity is $E=200 \mathrm{MPa}$; safety parameter is $\alpha=1.5$.

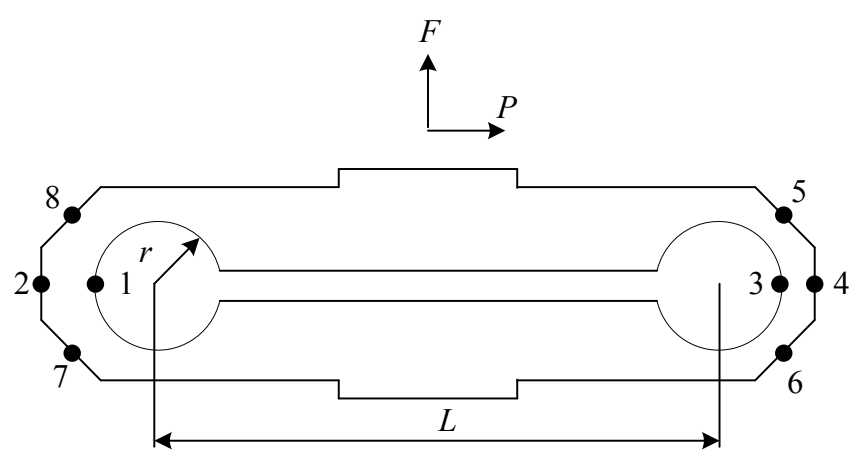

Fig. (1). The octagonal ring transducer. 
Under maximum load condition of the octagonal ring transducer, the design equation is as follows:

$\sigma_{\text {max }}=r\left[\begin{array}{l}2.62 F+2.17 P+ \\ \frac{4.05 M(2 k / \pi+0.5)}{r\left(k^{2}+4 / \pi+0.5\right)}\end{array}\right] / b t^{2}$,

$k=\frac{L}{2 r}$,

$M=F c+P d$,

where, $\mathrm{c}$ is distance of line of action of force $\mathrm{F}$ from centerline of the octagonal ring transducer, $d$ is distance of line of action of force $\mathrm{P}$ from top surface of the octagonal ring transducer, $\mathrm{L}$ is distance of the octagonal ring transducer, $b$ is thickness of the octagonal ring transducer, $r$ is mean radius of the octagonal ring transducer, $F$ is diametric force acting on the octagonal ring transducer, $\mathrm{P}$ is tangential force acting on the octagonal ring transducer, $\mathrm{n}$ is safety factor.

The design parameters were: $b=170 \mathrm{~mm}, r=50 \mathrm{~mm}$, $\mathrm{c}=600 \mathrm{~mm}, \mathrm{~d}=500 \mathrm{~mm}, \mathrm{t}=20 \mathrm{~mm}, \mathrm{~L}=230 \mathrm{~mm}, \mathrm{~h}=5 \mathrm{~mm}$.

There, $\sigma_{\max }<\frac{\sigma_{s}}{n}$.

Its strength can meet the design requirement.

\subsection{Calibration of the Octagonal Ring Transducer}

The position of the strain gauge paste is shown in Fig. (2) of the corresponding number $1 \sim 8$. The strain gauge of $1 \sim 4$ is for the test of the radial force bridge type circuit. The strain gauge bridge circuit of $5 \sim 8$ is for the test of the tangential force.

Link the force measuring device and the vibrating subsoiler; keep the vibrating subsoiler in place and use the connectors to link the octagonal ring transducers one by one with the up, down pull-rods. When the tractor drags the transducer, it is pulled and the radial force is calibrated. The tangential force is calibrated when heavy weights are loaded vertically.

The relation curve of the load of diametric force and bridge output voltage which is attained by using the LeastSquare fitting is shown as follow:

$y_{1}=0.0164 x_{1}+0.3708$,

$y_{2}=0.0165 x_{2}+0.2722$,

$y_{3}=0.0163 x_{3}+0.2978$,

where, $x_{1}$ is the load of diametric force on the octagonal ring transducer of upper link, $x_{2}$ is the load of diametric force on the octagonal ring of left lower link, $x_{3}$ is he load of diametric force on the octagonal ring transducer of right lower link, $y_{1}$ is the bridge voltage of transducer of upper link of diametric force, $y_{2}$ is the bridge voltage of transducer of left lower link of diametric force, $y_{3}$ is the bridge voltage of transducer of right lower link of diametric force. (a)

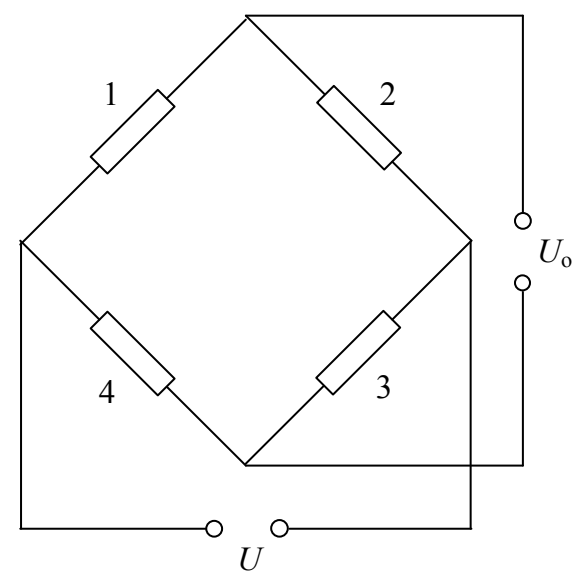

(b)

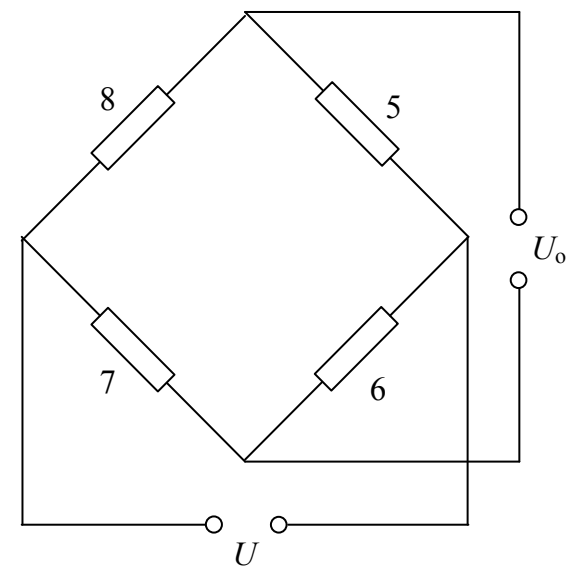

Fig. (2). The bridge circuit.

The relation curve of the load of tangential force and bridge output voltage which is attained by using the LeastSquare fitting is shown as follow:

$y_{4}=0.0104 x_{4}-5.266$,

$y_{5}=0.0104 x_{5}-5.327$,

$y_{6}=0.0102 x_{6}-5.365$,

where, $x_{4}$ is the load of tangential force on the octagonal ring transducer of upper link, $x_{5}$ is the load of tangential force on the octagonal ring transducer of left lower link, $x_{6}$ is the load of tangential force on the octagonal ring transducer of right lower link, $y_{4}$ is the bridge voltage of transducer of upper link of tangential force, $y_{5}$ is the bridge voltage of transducer of left lower link of tangential force, $y_{6}$ is the bridge voltage of transducer of right lower link of tangential force.

\section{EXPERIMENTS}

Vibratory subsoiler is mainly comprised of an eccentric shaft, furrow opener, vibrating arm, subsoiling shovel, depth wheels and etc. The eccentric shaft and vibrating arm are vibrating components. Its structural drawing is as shown in Fig. (3). 


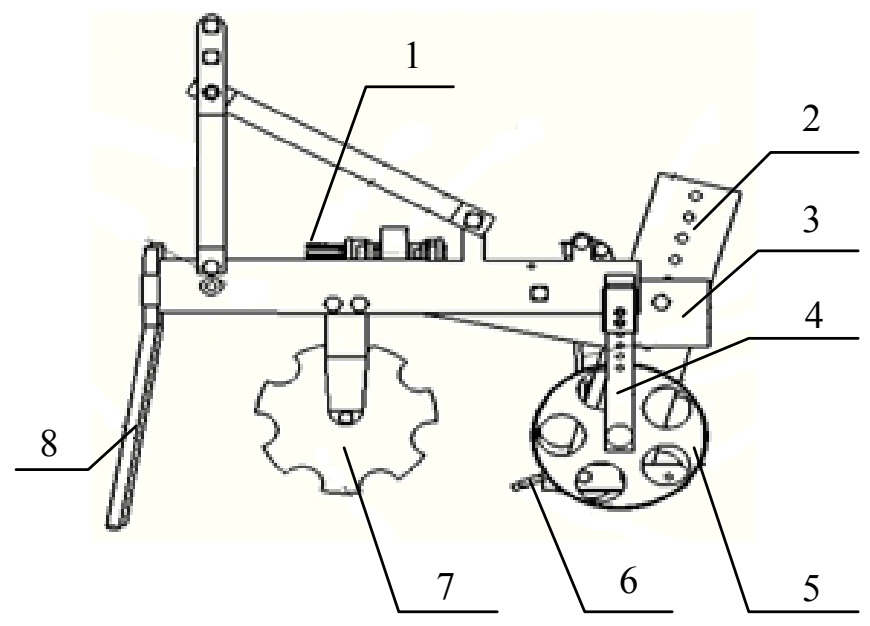

1-Eccentric shaft; 2-Share shaft; 3-Vibratory arm; 4-Bar; 5-Depth wheels; 6Shovel head; 7-Furrow opener; 8-Scaffold

Fig. (3). Vibratory subsoiler.

The tractor passes power to vibratory subsoiler eccentric shaft by the motive power output shaft, and keeps the vibratory arm vibrating up and down by the crank connecting rod mechanism. By this way, the subsoiling shovel will be driven to vibrate and the soil digging will occur. In the experiment, in order to realize the frequency, the rotating speed of the motive power output shaft will be changed and in order to change the amplitude, the crankshafts with the different eccentricity will be used.

The test system includes force measuring device, dynamic strain gauge, vibration measuring system, soil compactness measuring gauge, data acquisition system, vibrating subsoiler, and $35 \mathrm{kw}$-tractor. It is as shown in Fig. (4). One of the three octagonal ring transducers installed on the beam of the force measuring device frame tests the horizontal force and vertical force of the pull-rod of the tractor. The other one installed on the left post tests the horizontal force and vertical force of the pull-rod of the tractor on the left. In the same way, the last one installed on the right post tests the horizontal force and vertical force of the pull-rod of the tractor on the right. Octagonal ring transducer amplifies the signal by the six channel dynamic strain gauge. The data acquisition system gets the measuring data and the data acquisition program will store the data in the computer after processing. Two acceleration transducers will be installed on the tractor driver's seat and the shovel arm of subsoiling shovel, to test the tractor vibration and the vibration signals of the soiling shovel.

Use the vibrating subsoiler to carry out resistance reduction experiment in which the main influence factors are the vibration amplitude, vibration frequency, the tractor forward speed and the indicator is the traction resistance. Then the effect of these parameters on the traction resistance will be analyzed.

Taking three factors and three kinds of interaction, in which each interaction occupies two columns, into consideration, the number of the columns needed in orthogonal table is 9 . So the orthogonal table L27 $\left(3^{13}\right)$ is selected. According to the table of the interaction of the L27 $\left(3^{13}\right)$, the header design is designed. The three levels of the vibration amplitude, frequency, speed are as follows:
Vibration amplitude: $0.001 \mathrm{~m}, 0.002 \mathrm{~m}$, and $0.003 \mathrm{~m}$; Frequency: $9 \mathrm{~Hz}, 10 \mathrm{~Hz}$, and $12 \mathrm{~Hz}$; Speed: $0.1 \mathrm{~m} / \mathrm{s}, 0.2 \mathrm{~m} / \mathrm{s}$, and $0.3 \mathrm{~m} / \mathrm{s}$. The data measured is showed in Table 1 and the analysis of the results of the three levels orthogonal experiment is showed in Table 2 .

(a)

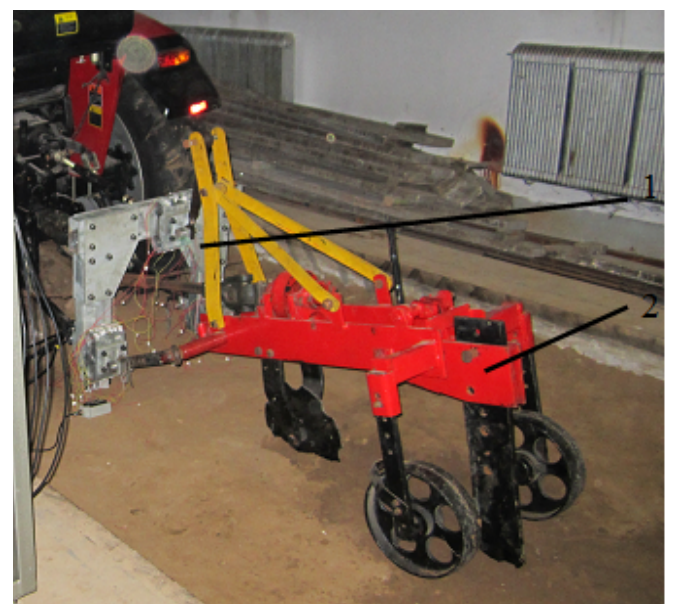

(b)

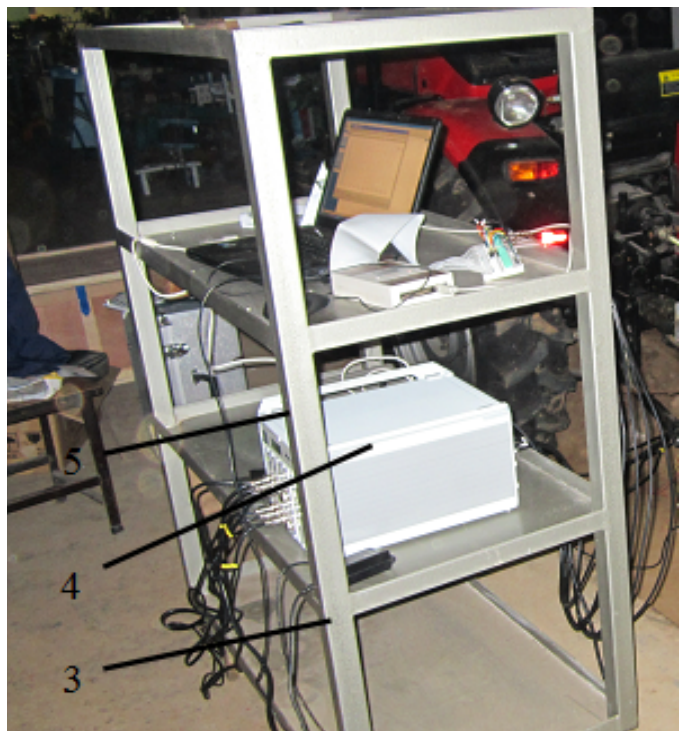

1-The force measuring device; 2-Vibratory subsoiler; 3-Dynamic strain gauge; 4-Data acquisition system; 5-Vibration test system

Fig. (4). Test equipment.

\section{VARIANCE ANALYSIS}

The Table 2 shows that the influence of the interaction factors $\mathrm{A}, \mathrm{B}$ and $\mathrm{A} * \mathrm{C}$, are of great significance for the experiment results. The influence of the interaction of $\mathrm{C}, \mathrm{A}$ and $\mathrm{B}^{*} \mathrm{~B} * \mathrm{C}$, is also of significance to the experiment results. The experiment results are shown below.

(1) When vibration frequency is the same, speed is 0.2 $\mathrm{m} / \mathrm{s}$, the amplitude is $0.001 \mathrm{~m}$, the traction resistance value is lower than the one when the amplitude is $0.002 \mathrm{~m}$; When the vibration frequency is the same and amplitude is $0.003 \mathrm{~m}$, and forward speed is 0.1 $\mathrm{m} / \mathrm{s}$, the traction resistance is lower than the one when the speed is $0.2 \mathrm{~m} / \mathrm{s}, 0.3 \mathrm{~m} / \mathrm{s}$. 
Table 1. The experimental data.

\begin{tabular}{|c|c|c|c|c|c|c|c|c|c|c|}
\hline Test Number & 1 & 2 & 3 & 4 & 5 & 6 & 7 & 8 & 9 & Traction Resistance \\
\hline & $\mathrm{A}$ & B & $(A * B) 1$ & $(\mathrm{~A} * \mathrm{~B}) 2$ & $\mathrm{C}$ & $\left(A^{*} \mathrm{C}\right) 1$ & $\left(A^{*} \mathrm{C}\right) 2$ & $\left(B^{*} \mathrm{C}\right) 1$ & $\left(B^{*} \mathrm{C}\right) 2$ & $(\mathrm{kN})$ \\
\hline 2 & 1 & 1 & 1 & 1 & 2 & 2 & 2 & 2 & 2 & 2.51 \\
\hline 3 & 1 & 1 & 1 & 1 & 3 & 3 & 3 & 3 & 3 & 3.05 \\
\hline 5 & 1 & 2 & 2 & 2 & 2 & 2 & 2 & 3 & 1 & 2.37 \\
\hline 6 & 1 & 2 & 2 & 2 & 3 & 3 & 3 & 1 & 2 & 2.66 \\
\hline 7 & 1 & 3 & 3 & 3 & 1 & 1 & 1 & 3 & 2 & 2.87 \\
\hline 8 & 1 & 3 & 3 & 3 & 2 & 2 & 2 & 1 & 3 & 2.8 \\
\hline 12 & 2 & 1 & 2 & 3 & 3 & 1 & 2 & 3 & 3 & 3.23 \\
\hline 13 & 2 & 2 & 3 & 1 & 1 & 2 & 3 & 2 & 3 & 3.17 \\
\hline 14 & 2 & 2 & 3 & 1 & 2 & 3 & 1 & 3 & 1 & 3.14 \\
\hline 15 & 2 & 2 & 3 & 1 & 3 & 1 & 2 & 1 & 2 & 3.19 \\
\hline 16 & 2 & 3 & 1 & 2 & 1 & 2 & 3 & 3 & 2 & 3.34 \\
\hline 17 & 2 & 3 & 1 & 2 & 2 & 3 & 1 & 1 & 3 & 3.18 \\
\hline 18 & 2 & 3 & 1 & 2 & 3 & 1 & 2 & 2 & 1 & 3.2 \\
\hline 19 & 3 & 1 & 3 & 2 & 1 & 3 & 2 & 1 & 1 & 3.01 \\
\hline 25 & 3 & 3 & 2 & 1 & 1 & 3 & 2 & 3 & 2 & 3.11 \\
\hline 26 & 3 & 3 & 2 & 1 & 2 & 1 & 3 & 1 & 3 & 3.18 \\
\hline 27 & 3 & 3 & 2 & 1 & 3 & 2 & 1 & 2 & 1 & 3.15 \\
\hline
\end{tabular}

Table 2. Variance analysis.

\begin{tabular}{|c|c|c|c|c|}
\hline Source of Variation & SS & df & MS & F \\
\hline \hline A & 1.05 & 2 & 0.52 & 72.5 \\
\hline B & 0.15 & 4 & 0.072 & 5.0 \\
\hline A*B & 0.15 & 2 & 0.036 & 4.0 \\
\hline C & 0.06 & 4 & 0.203 & 27.9 \\
\hline A*C & 0.81 & 4 & 0.012 & 1.64 \\
\hline B*C & 0.04 & 8 & 0.007 & \\
\hline
\end{tabular}

(2) When the speed is the same, the amplitude is 0.001 $\mathrm{m}$, and $0.002 \mathrm{~m}$ and the frequency of vibration is 10 $\mathrm{Hz}$, then the traction resistance is lower than the one when the frequency is $9 \mathrm{~Hz}, 12 \mathrm{~Hz}$. This is because the soil is easily broken and traction resistance is smaller when the vibration frequency is relatively 
close to the inherent frequency of the soil and the system produces resonance. When speed is the same, the amplitude is $0.003 \mathrm{~m}$ and the frequency of vibration is $9 \mathrm{~Hz}$, traction resistance is lower than the one when the frequency of vibration is $10 \mathrm{~Hz}$ and 12 $\mathrm{Hz}$.

\section{CONCLUSION}

The vibratory resistance reduction force measuring device is designed in the paper. It's up, down, left and right margin of the frame is adjustable. Besides, it should be linked to the different kinds of vibratory subsoilers and tractors. The analysis results are based on the vibrating subsoiler's vibrating resistance reduction experiments and the orthogonal design and variance analysis. It shows that with the same speed and bigger vibration frequency, the tractor traction resistance is small and when the amplitude is $0.001 \mathrm{~m}$, the vibration frequency is $10 \mathrm{~Hz}$, and forward speed is $0.2 \mathrm{~m} / \mathrm{s}$, the tractor traction resistance is the minimum. When vibration frequency is the same, speed is $0.2 \mathrm{~m} / \mathrm{s}$, the amplitude is $0.001 \mathrm{~m}$, the traction resistance is small; when the vibration frequency is the same, the amplitude is $0.003 \mathrm{~m}$ and speed is $0.1 \mathrm{~m} / \mathrm{s}$, the traction resistance is small. When the forward speed and the amplitude are the same and the frequency of vibration is $10 \mathrm{~Hz}$, the traction resistance is small. The study above shows that all of the three factors, amplitude, speed and frequency all have significant influence on the tractor's traction resistance and under special working condition, the traction resistance is small. So the conclusion is that the vibrating subsoiler's traction resistance will be reduced, energy consumption will be decreased and subsoiling effect will be better if the farming tractor has the functions of amplitude modulation and frequency modulation.

\section{CONFLICT OF INTEREST}

The authors confirm that this article content has no conflict of interest.

\section{ACKNOWLEDGEMENTS}

This work is financially supported by the National Natural Science Foundation of China under Grant No.51105259 and by the Talent Plan of Liaoning Province.

\section{REFERENCES}

[1] M. J. O. Dogherty, "The design of octagonal ring dynamometers", J. Agric. Eng. Res, vol. 63, pp. 9-18, 1996.

[2] A. Yousef, and H. Sina "Extended Octagonal Ring Transducers for Measurement of Tractor Implement Forces", Instrum. Exp. Tech., vol.54, no. 1, pp. 136-140, 2011.
[3] P. P. Nalavade, V. M. Salokhe, T. Niyamapa, and P. Soni, "Performance of free rolling and powered tillage discs", Soil Tillage Res., vol. 109, pp. 87-93, 2010.

[4] R. J. Godwin, A. J. Reynolds, M. J. O Dogherty, and A. A. AlGhazal, "A triaxial dynamometer for force and management measurement on tillage implements", J. Agric. Eng. Res., vol. 55, pp. 189-205, 1993.

[5] G. Wu, J. Song, Y. Li, and J. Wang, "Design and experiment on vibration spacing scarifier for meadow", Trans. Chin. Soc. Agric. Mach., vol. 41, no. 2, pp. 42-46.

[6] X. Dong, J. Song, J. Wang, Y. Li and G. Wu, "Working mechanism of vibration spacing scarifier for grassland", Trans. CSAE, vol. 26, no. 10, pp. 119-123, 2010.

[7] G. H. Shahgoli, F. John, D. Jacky, and S. Chris, "Optimising oscillation frequency in oscillatory tillage", Soil Tillage Res., vol. 106, pp. 202-210, 2010.

[8] X. Li, J. Fu, D. Zhang, C. Tao, and Z. Rui, "Experiment analysis on traction resistance of vibration subsoiler", Trans. CSAE, vol. 28, no. 1, pp. 32-36, 2012.

[9] X. Zhao, X. Luo, and L. G. Wells, "Development of continuous measurement system for soil resistance", Trans. CSAE, vol. 25, no. 2, pp. 67-71, 2009.

[10] Y. Chen, N. B. McLaughlin, and S. Tessier, "Double extended octagonal ring (DEOR) drawbar dynamometer", Soil Tillage Res., vol.93, pp. 462-471, 2007

[11] M. J. Hann, and J. Giessible, "Force measurements on driven discs", J. Agric. Eng. Res., vol. 69, pp. 149-157, 1998.

[12] D. R. P. Hettiaratchi, "The soil contact zones of concave agricultural discs: part 1 - theoretical analysis", J. Agric. Eng. Res., vol. 67, pp. 113-125, 1997

[13] D. R. P. Hettiaratchi, "Prediction of soil forces acting on concave agricultural discs", J. Agric. Eng. Res., vol. 68, pp. 51-62, 1997.

[14] D. R. P. Hettiaratchi, M. M. Alam, "Calculation, validation and simulation of soil reactions on concave agricultural discs", J. Agric. Eng. Res., vol.68, pp. 63-75, 1997.

[15] M. S. Islam, V. M. Salokhe, C. P. Gupta, M. Hoki, "Effects of PTO-powered disk tilling on some physical properties of Bangkok clay soil", Soil Tillage Res., vol. 32, pp. 93-104, 1994.

[16] U. D. Perdok, J. K. Kouwenhoven, "Soil-tool interactions and field performance of implements", Soil Tillage Res., vol. 30, pp. 283326,1994 .

[17] S. Majumdar, E. V. Thomas, and D. S. Jayas, "Optimization of parameters in the design of an extended octagon-ring transducer", Agric. Eng. J., vol. 3, pp. 152-165, 1994.

[18] R. M. Brewer and M. L. Hull, "The effect of interface plate compliance on dynamometers incorporating octagonal strain rings", Exp. Mech., vol. 35, no. 4, pp. 337-344, 1995.

[19] P. E. Young, "A machine to increase productivity of a tillage operation", Trans. ASAE, vol. 19, no. 6, pp. 1055-1061, 1976.

[20] V. M. Salokhe, and N. B. A. Quang, "Dynamics of powered disc in clay soil", J. Terramech., vol. 32, no. 5, pp. 231-244, 1995.

[21] P. E. Young, "A machine to increase productivity of a tillage operation", Trans. ASAE, vol. 19, no. 6, pp. 1055-1061, 1976.

[22] C.A. Chen and N.A. Duffie, "Development of an automatic surface finishing system (ASFS) with in-process surface topography inspection", J. Mater. Proc. Technol., vol. 62, no. 4, pp. 427-430, 1996.

[23] Y. Zhe-Jun, C. Li-Jun, and Z. Pan, "A new type of threecomponent dynamometer with high stiffness and high natural frequency," In: Proc. 26 th Int. M.T.D.R. Conf., B.J. Davis, Ed., Palgrave Macmillan Press, pp. 313-316, 1987. 